\title{
MODERNIDAD Y APOCALIPSIS EN LOS ZORROS DE ARGUEDAS
}

\author{
Lucero de Vivanco \\ Universidad Alberto Hurtado \\ lucero@mi.cl
}

RESUMEN / ABSTRACT

Se propone en este artículo una lectura de El zorro de arriba y el zorro de abajo en clave apocalíptica. Las distintas textualidades que atraviesan la novela -los diarios del autor, los mitos pre-hispánicos y la fábula narrativa propiamente tal- se articulan con características específicas del apocalipsis para representar el colapso social producido por la modernidad capitalista en el Perú de la década del setenta.

PALABRAS ClAVE: literatura peruana, modernidad, apocalipsis, imaginario, Arguedas.

The present article proposes a reading of El zorro de arriba y el zorro de abajo from an apocalyptic perspective. The different textual layers interwoven in the novel-the author's diaries, the pre-hispanic myths and the narrative plot itself-are articulated in a way that resonates specifically with the apocalypsis in order to represent the social collapse brought on by capitalist modernity in Peru during the seventies.

KEY WORDS: Peruvian literature, modernity, apocalypse, imaginary, Arguedas.

El zorro de arriba y el zorro de abajo (1971) de José María Arguedas coincide con otras novelas peruanas en que el apocalipsis constituye en ellas un sistema interpretativo a través del cual autor y lector se vinculan con el referente en las distintas instancias de producción y recepción textual. El vínculo que se establece tiene un carácter singular, lo que viene dado tanto por la naturaleza del referente cuanto por las características del sistema interpretativo 
propuesto: la complejidad de un país que acusa la persistencia a lo largo del tiempo de sus problemas sociales más profundos; busca legibilidad en los términos radicales que le ofrece el imaginario apocalíptico, estableciéndose una relación cuyo propósito parece ser el de recomponer un pacto con sentido entre el ser humano y el mundo.

El Perú ha estado siempre -y lo sigue estando- lejos de responder a un proyecto armónico, homogéneo e integrado. Por el contrario, si algo hay que caracterice a este país es el carácter desarticulado, multicultural y de conflictivas diferencias al interior de su sociedad, condiciones que arrancan con el ingreso (usando un eufemismo) de los españoles al Perú. Históricamente, los grupos políticos dominantes, una vez lograda la emancipación y durante la época republicana, no han sido capaces de liderar un proyecto de Estado nacional ni de legitimar sus programas a nivel de la sociedad peruana en su conjunto. Por el contrario, la República ha pasado por distintas etapas en las que el poder estatal permitió y propició un modo de producción capitalista que favorecía únicamente a las clases oligárquicas y aristocráticas -y a una incipiente burguesía- centralizadas en Lima y en otros sectores de la costa del Perú. Simultáneamente, el Estado 'facilitó' en el campo y en la sierra la prolongación del modelo 'feudal' colonial con el fortalecimiento del sistema de haciendas bajo el poder absoluto de terratenientes y 'gamonales' que levantaron sus posesiones, en muchos casos, a partir del despojo de tierras a los indígenas con la anuencia de las autoridades locales. En el largo plazo, esto tuvo como consecuencia el paulatino y luego acelerado desplazamiento de campesinos hacia zonas urbanas costeñas a partir de la década del cuarenta, de lo cual la ciudad de Chimbote sería un ejemplo; la aguda pauperización del campo que se expresa de manera organizada en las movilizaciones campesinas a partir de fines de la década del cincuenta; y la irrupción de la violencia política que tuvo su momento cúspide en la guerra de Sendero Luminoso a partir de la década de los ochenta.

En este complejo escenario, desigual y polarizado, se 'gesta' una literatura peruana que reproduce la composición conflictiva y discontinua de su sociedad. "No es una literatura armoniosamente unitaria, y no podía serlo", afirma García-Bedoya, "pues surge de una realidad social desgarrada, fruto del choque violento entre dos culturas, en la que una -la occidental española- impone su dominación por la fuerza a la otra -la andina-" (54). Antonio Cornejo Polar ha introducido en el ámbito de la teoría y la crítica literaria latinoamericana el concepto de "heterogeneidad" para esclarecer el vínculo complejo entre el sistema literario y el proceso histórico de la sociedad 
peruana y para dar cuenta de las expresiones 'literarias' desiguales que conforman lo que tradicionalmente se conoce como 'literatura peruana'.

Sin embargo, la situación es aún más compleja. Cornejo Polar considera que la literatura peruana ha logrado su mayor consistencia las veces que se ha propuesto "revelar y juzgar la realidad de la que emana" (Literatura peruana 136). Es decir, dentro del ineludible cruce entre literatura y sociedad propuesto por el crítico peruano, la literatura no solo ha surgido de la situación de heterogeneidad conflictiva de esta sociedad sino que ha encaminado sus energías artísticas a referirse a esa realidad social de la que procede. En su voluntad de recoger, transcribir, comunicar y, por supuesto, construir el Perú, su especificidad y su identidad, la literatura peruana ha debido soportar lo que Cornejo Polar ha descrito como una "doble y contradictoria solicitación: ... de un lado, actúan los condicionamientos propios de una sociedad subdesarrollada, sociedad cuyos conflictos quieren ser esclarecidos por la literatura, y de otro, los modelos que propone la literatura de los países desarrollados, los únicos accesos a la modernidad y a la universalidad" (Literatura peruana 136). Por lo tanto, la heterogeneidad responde no solo a fuerzas internas (realidad social compleja, sistemas literarios diferentes y/o con cruces entre ellos) sino también a fuerzas externas a las fronteras nacionales, las que permitirían y serían inevitables para 'traducir', dar legibilidad 'universal' a la "irresuelta conflictividad del Perú" (Literatura peruana 137$)$.

De todo lo arriba mencionado, parece imprescindible relevar tres ideas. Primero, la situación de "irresuelta conflictividad" social y económica del Perú, como la llamó Cornejo Polar. Segundo, una literatura peruana que, en uno de sus rasgos más sólidos -siguiendo a Cornejo Polar-, se interesa por dar cuenta de sus condiciones sociales y de las fuerzas en contienda que conforman el Perú. Tercero, un sistema literario que asume modelos, formas, estructuras, imaginarios cosmopolitas, en muchos casos componiendo sistemas heterogéneos, con el propósito de 'universalizar' el relato sobre el Perú y sobre su realidad social. Un buen número de novelas peruanas publicadas entre 1960 y $1990^{1}$ responde con bastante lealtad a las tres ideas

${ }^{1}$ Crónica de San Gabriel (1960) y Los geniecillos dominicales (1965) de Julio Ramón Ribeyro, las cinco novelas que componen La guerra silenciosa (1970-1979) de Manuel Scorza, Pantaleón y las visitadoras (1973) e Historia de Mayta (1984) de Mario Vargas Llosa, Mañana, las ratas (1984) de José Adolph, y la trilogía que conforma Dos señoras conversan (1990) de Alfredo Bryce Echenique, serían algunas de ellas. 
expuestas: en ellas hay en alguna medida y forma una construcción ficcional que hace referencia al Perú en el difícil, crítico y violento periodo que marcan estas décadas; demuestran además un interés por representar y re-construir ese referente con moldes que lo hagan inteligible para la cultura occidental.

Tanto en El zorro de arriba y el zorro de abajo como en otras novelas peruanas del periodo, el imaginario propuesto para hacer legible la realidad social proviene del apocalipsis que, en términos de género, surge de la necesidad de 'revelar' un contexto de conflictividad social, de otorgarle un sentido a dicha situación y de despertar el anhelo de transformación. Tal vez aquí resida la respuesta a por qué el imaginario apocalíptico en la literatura peruana está en muchos casos ligado a sus rasgos identitarios y resulte ad hoc como herramienta interpretativa: situaciones de crisis y conflictividad son también las que están en la base de la conformación -o más bien de la dificultad de conformación- del Perú como nación. En este sentido, se explicaría la frecuencia con la que aparece este imaginario en la literatura peruana, especialmente tratándose de un imaginario con el que se ha interpretado el origen o la causa de la mencionada conflictividad, es decir, el choque cultural hispano-indígena. En otras palabras, el imaginario apocalíptico llega al Perú junto con la experiencia traumática y desgarradora de la conquista y renueva constantemente su vigencia precisamente porque se mantienen las condiciones sociales establecidas a partir de dicha experiencia traumática. Dio legibilidad a ese episodio histórico y sigue dando legibilidad a los problemas no resueltos generados a partir de dicho episodio.

Gran parte de la literatura crítica sobre la tradición apocalíptica está orientada a la exégesis del Apocalipsis de Juan, último libro de la Biblia. De hecho, el Apocalipsis es uno de los textos bíblicos que más páginas interpretativas ha sumado a lo largo de la historia intentando ser comprendido, pero logrando pocos acuerdos entre los exégetas acerca de su mensaje y propósito $^{2}$ (McGinn 15). El hecho de que existan distintos modos posibles de acercarse al apocalipsis y de que los métodos, además, hayan variado en el tiempo de acuerdo a las tendencias doctrinales y/o literarias, ha dificultado cualquier intento de construir una explicación o valoración única de la visión

2 Dice Bernard McGinn sobre el Apocalipsis: "it is difficult to find two modern interpreters who would agree on the best way or ways to elucidate its essential message" (15). Sobre los distintos métodos exegéticos utilizados históricamente para interpretar la Biblia y las ventajas del análisis retórico sobre otros tipos de análisis, véase Roland Meynet. 
de Juan. Sin embargo, Roland Meynet da una clave aparentemente inocente pero útil cuando de lo apocalíptico se trata y, especialmente, cuando de la literatura apocalíptica peruana se trata: solicita situar siempre los textos bíblicos en el "contexto institucional e histórico en el que se formaron y del que son testigos" (41). Esto levanta el sentido político del discurso apocalíptico, gesto que se repite actualmente como en su origen, cuando se focalizaba en revelar la condición de crisis, persecución e intolerancia social y religiosa de judíos y primeros cristianos, en subvertir dicha condición y en generar una transformación, como ha enfatizado Lois Parkinson.

Por otro lado, autores como Parkinson y Frank Kermode han vertido sus esfuerzos, partiendo del mismo libro de Juan, en indagar sobre aquellos elementos apocalípticos que permiten objetivar y establecer lo apocalíptico como género literario ${ }^{3}$, destacando, consecuentemente, los motivos recurrentes en esta también llamada 'literatura apocalíptica'. Uno de los más importantes es el output subversivo recién señalado, que proviene de la consideración de la instancia contextual. Anticipo otros dos motivos que aparecen en la novela de Arguedas que nos ocupa. El primero, la alegorización del lenguaje y la ambivalencia de los contenidos, lo que responde a la doble característica del apocalipsis de ocultar y revelar al mismo tiempo y que recae también sobre el narrador, dada su doble misión de decodificar y recodificar lo que le está siendo revelado. El segundo motivo dice relación con la orientación teleológica de la estructura narrativa del apocalipsis, como ha señalado Kermode, la que se organiza dentro de una concepción lineal de la historia, tensionando la concordancia entre el principio y el fin y proyectando un término que debiera coincidir con la finalidad en orden a dar sentido a toda la estructura. La narrativa literaria y la apocalíptica coinciden, según la tesis de Kermode, en que ambas están fundadas en una necesidad antropológica de proyectar finales con sentido.

${ }^{3}$ El concepto de género en este caso se entiende bajo un carácter dinámico y transtextual, como lo propone Jean Marie Schaeffer. Según este autor, la genericidad puede explicarse como un juego de repeticiones, imitaciones y préstamos a nivel textual, pero también a nivel formal y temático. Lo apocalíptico como género, según esta aproximación, tiene sus orígenes en los textos proféticos del Antiguo Testamento, a partir de los cuales el libro de Juan en el Nuevo Testamento reitera y reelabora aspectos formales (estructuras narrativas, temporales; estrategias enunciativas y retóricas) y temáticas (escatológicas y proféticas). Para el género apocalíptico, además de Parkinson y Kermode, véase Camile Focant, "El Apocalipsis de Juan”. 
En este marco, El zorro de arriba y el zorro de abajo puede pensarse bajo el imaginario apocalíptico: un gesto especulativo cuya forma 'interrogativa' recae sobre el Perú y los peruanos; su historia y su destino; sus migraciones y sus intentos modernizadores; sus leyes y sus prácticas sociales; los imaginarios que describen a la nación, la construyen y la representan; la función de sus instituciones y las necesidades de su gente; sus deseos, temores, creencias, anhelos.

Lo anterior se formula sin olvidar que El zorro de arriba y el zorro de abajo es una de las ficciones peruanas más complejas y que más tinta ha demandado a la labor crítica ${ }^{4}$. Compuesta a partir de tres textualidades diferentes, las que eslabonan los diarios del autor, los mitos prehispánicos y la fábula narrativa propiamente tal, el texto ha sido leído desde claves teóricas, culturalistas, mitológicas, lingüísticas, intertextuales, folclóricas, biográficas, entre otras ${ }^{5}$, justamente por la diversidad hermenéutica que ofrece al lector. Su riqueza interpretativa proviene tanto de la articulación de los tres estratos discursivos que la componen cuanto del hecho que en ella el autor anuncia su próximo suicidio, el que concreta dejando inconclusa la novela, abriendo en extremo el espectro de lecturas posibles. Este acontecimiento impregna el texto y las interpretaciones del mismo con el sino de la tragedia humana y aproxima visceralmente la literatura a la relación agónica y precaria entre la vida y la muerte. La lectura que aquí se propone parte de este poco amoenus locus enunciativo, apocalíptico por derecho propio, en el que la crisis colectiva se encarna en el individuo, para enhebrar desde allí al menos tres motivos apocalípticos posibles, en concordancia con las tres discursividades presentes en la novela.

Efectivamente, el apocalipsis aparece en primer lugar a través de la escena íntima y confesional: los diarios personales del autor, una de las tres

${ }^{4}$ En el mismo sentido apunta Cecilia Esparza: "El zorro de arriba y el zorro de abajo constituye una novela difícil de asimilar por la crítica literaria y es, por cierto, la obra más polémica y menos estudiada de Arguedas. Las opiniones oscilan entre posturas que ponen en evidencia el desconcierto ante una novela que se considera «experimental», hasta posturas que consideran la novela como un producto fallido sin valor estético" (76).

5 Véase, por ejemplo: Antonio Cornejo Polar (Los universos narrativos), Martín Lienhard (“Tradición oral”), Gracia María Morales Ortiz ("'Heterogeneidad' y 'Totalidad'”), Jesús Díaz Caballero ("La transculturación"), Edita Vokral ("Arguedas como dansak"), William Rowe ("Música, conocimiento"), Liliana Befumo Boschi y Aymara de Llano ("El escritor y el hombre"). 
textualidades con las que la novela se construye. Intercalados a lo largo del texto, estos diarios, escritos entre Lima y Santiago, discurren espontánea y libremente por asuntos preferentemente literarios: sus ideas sobre la escritura, su posición frente a otros escritores latinoamericanos, sus viajes a la ciudad-puerto de Chimbote con el propósito de instruirse para esta novela que ambienta en ese lugar. Del mismo modo, recuerdos de su infancia en la sierra y algunas ulteriores reflexiones sobre la situación del Perú se suman a sus páginas. Pero lo que marca el tono narrativo de estos diarios, así como su temple trágico y hace que en esta construcción discursiva pueda leerse la intervención del imaginario apocalíptico es la presentación de la muerte del autor, por el propio autor, como un hecho inminente. La primera página del "Primer diario" (es decir, el inicio mismo de la novela) lo reseña así: "En abril de 1966, hace ya algo más de dos años, intenté suicidarme. ... Y ahora estoy otra vez a las puertas del suicidio" (11). El fantasma acuciante de la muerte despliega al menos tres motivos apocalípticos posibles, en concordancia con las tres discursividades presentes en la novela.

El más evidente de estos motivos es el tono de urgencia que se impone a la narración y que se marca de manera fundamental en los diarios. Dada la coincidencia - como ha señalado Parkinson para el género canónico- del tiempo con el que se cuenta para narrar, por un lado, con la narración del fin del tiempo propiamente tal, por el otro, el acto enunciativo es urgente y vehemente. De esta naturaleza es, en la novela de Arguedas, la angustia cada vez mayor que aparece a lo largo de los diarios, la que urge por avanzar y dar término al relato antes de concretar la decisión de dar término a la propia vida. Incluso, en el "Primer diario", es la escritura la que retrasa la muerte: "Porque yo si no escribo y publico, me pego un tiro" (21), confesó Arguedas. En el "Segundo diario", el autor enfatiza la dificultad para escribir y el cada vez más corto plazo para hacerlo: "Mañana, o pasado, o el lunes, comienzo el capítulo III a como dé lugar. He pedido, para escribir este libro, diez meses de licencia sin sueldo en la Universidad, y ya han pasado cuatro y medio. No puedo huevear más tiempo. Y no vuelvo más al puerto hasta terminar el trabajo o reventar. ... ¡Tengo miedo, no puedo empezar este maldito capítulo III, de veras!" (99). En su "Tercer diario" da testimonio de su agravamiento: "Volví de Arequipa en tal estado de animación y lucidez que pensé que terminaría de escribir el libro en los tres meses que me faltan para incorporarme a la Universidad. Dos días trabajé en la continuación del IV capítulo. Luego, caí en un estado de postración tan lóbrego como los que me atacan en los últimos veinte años y de los que salgo cada vez con mayor agonía" (208). 
En la literatura peruana apocalíptica, la búsqueda -o la necesidad- de coincidencia entre acto de enunciación y enunciado en las narraciones en que ambos (enunciación y enunciado) refieren al discurrir temporal aparece de distintas maneras. Para mencionar un par de casos, podemos señalar que en Dos señoras conversan de Alfredo Bryce Echenique, el narrador termina la novela, podría decirse, por agotamiento, dado que el fin redentor esperado por y para sus personajes no se concreta: Bryce deja a sus dos mujeres conversando, amenazadas por un final que se perpetúa en su inminencia. El sinsentido de una vida sin redención es la comprensión apocalíptica que se ofrece al lector de Bryce cuando enfrenta un final de esta naturaleza. Por el contrario, al término de las cinco novelas que componen La guerra silenciosa de Manuel Scorza, el narrador relata el fracaso de la empresa épica de los comuneros indígenas que luchan por sus legítimos derechos, dando cuenta del fin de una posibilidad social y cultural anclada en los Andes del Perú. Al lector de Scorza le aguarda ya no la comprensión de un sinsentido sino la de un sentimiento de frustración o rabia, porque el fin sí se ha concretado pero no la justicia compensatoria. Pero El zorro de arriba y el zorro de abajo es la única novela apocalíptica peruana donde el tiempo de la enunciación se interrumpe abrupta y voluntariamente sin que el enunciado concluya. Arguedas informa en su “¿Último diario?” el desenlace que había pensado dar a los conflictos y a los personajes de la novela, pero confiesa simultáneamente que la muerte lo ha derrotado y que no podrá concluir la tarea de darle la corporalidad proyectada: "He luchado contra la muerte o creo haber luchado contra la muerte, muy de frente, escribiendo este entrecortado y quejoso relato. Yo tenía pocos y débiles aliados, inseguros; los de ella han vencido. Son fuertes y estaban bien resguardados por mi propia carne. Este desigual relato es imagen de la desigual pelea" (283).

Dada la fatal imbricación entre los diarios personales y la trama narrativa, la supresión del narrador se proyecta también sobre lo narrado. El silencio de Arguedas implica la disolución del mundo que estaba en proceso de construcción. ¿Cómo se ha interpretado este acontecimiento a la vez vital y literario? En muchos sentidos. Para citar dos extremos: Vargas Llosa se queja de un "chantaje al lector" y de una "trampa sentimental" (La utopía 300), dado que el suicidio, cree él, inocula en el texto un valor que no tendría sin él; Julio Ortega ve más bien "un sentido creativo aún en la violencia y la autodestrucción" ("Los Zorros" s/n), algo así como una posibilidad renovadora que proviene de una concepción mítica andina, de tiempo circular, en el que la vida toma su origen de la muerte. ¿Y cómo interpretarlo en 
términos apocalípticos? Si algo puede afirmarse del apocalipsis es que, a pesar de la innegable y concreta presencia en el imaginario social y cultural, éste no deja de ser un relato de sentido. Su existencia es solo una promesa narrativa, su característica plenaria es su incumplimiento. Existe por este relato y se actualiza cada vez que vuelve a narrarse en un determinado contexto histórico. Por lo tanto, si no hay narración no hay apocalipsis. Arguedas, al detener el relato, también ha detenido el apocalipsis que iba sumiendo a la ciudad de Chimbote y a sus habitantes en una catástrofe urbana y social. Pero el sentido del relato no se pierde sino que se transfiere a su muerte, con la que el autor de los zorros pretende alcanzar la realidad del Perú que excede a la ficción. Cabe para su acto suicida, entonces, una lectura sacrificial; su muerte anula el apocalipsis de Chimbote en su faceta más destructiva, dejando únicamente lo que de esperanza y deseo utópico contiene también el relato del Fin. El impulso mítico del Pachacuti, el que enlaza destrucción con renovación, parece conferirle sentido a su deceso, transfigurando los elementos distópicos ${ }^{6}$ de la ciudad-puerto en fundamentos utópicos para el Perú. Las últimas líneas del texto revelan este anhelo:

Quizá conmigo empieza a cerrarse un ciclo y a abrirse otro en el Perú y lo que él representa: se cierra el de la calandria consoladora, del azote, del arrieraje, del odio impotente, de los fúnebres "alzamientos", del temor a Dios y del predominio de ese Dios y sus protegidos, sus fabricantes; se abre el de la luz y de la fuerza liberadora invencible del hombre de Vietnam, el de la calandria de fuego, el del dios liberador, Aquel que se reintegra. Vallejo era el principio y el fin ${ }^{7}$ (287).

En la interrelación entre la experiencia vital y la literaria que emerge de la particular situación enunciativa de la novela, aparece un segundo motivo apocalíptico: la condición crítica del contexto en el que se origina este relato de sentido, que nos conduce también al segundo estrato textual: el mundo narrativo propiamente tal, la ciudad-puerto de Chimbote, al norte de Lima.

${ }^{6}$ El Diccionario del español actual define 'distopía' como una "situación imaginaria en que todo es lo peor que puede ser. Se opone a Utopía” (Seco, Diccionario s.v. “distopía”). En oposición al concepto 'utopía' y recogiendo el valor negativo del prefijo griego $d y s$, podría definirse la 'distopía' como un mal lugar o un lugar de desgracias del cual se desea o espera salir, y lo 'distópico' como lo perteneciente o relativo a la distopía.

${ }^{7}$ Véase Ap. 22:13: "Yo soy el Alfa y la Omega, el principio y el fin, el primero y el último". 
Todo apocalipsis surge en un contexto de crisis, ha señalado Parkinson, como una luz de esperanza, compensación y justicia tras un camino de sufrimiento. El propio Apocalipsis bíblico está escrito por un Juan perseguido y exiliado en la isla griega de Patmos. En la novela de Arguedas, precisamente por la estrecha conexión que se ha establecido entre la muerte y la escritura, no se puede pensar que la relación entre el contexto histórico y la narración apocalíptica es de una sola dirección. No son únicamente las condiciones materiales e históricas de Chimbote las que han disparado la representación de la ciudad en términos de este imaginario en particular. También es legítimo pensar, y así lo ha hecho más de un estudioso de su obra ${ }^{8}$, que son las circunstancias críticas del autor las que proyectaron el mundo apocalíptico en su narración. Esto quiere decir que el apocalipsis, en este caso, articula dos 'crisis' distintas. La primera se define teóricamente en términos de una colectividad afectada que, eventualmente, proyecta su fin en función de una redención también colectiva: un fin de mundo, un actor mesiánico, una segunda venida de Cristo, una revolución que invierta el orden que genera

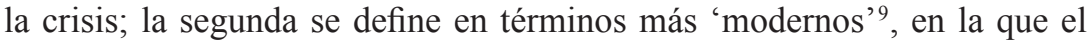
individuo se enfrenta con un final que ya no se proyecta en términos colectivos sino de la propia muerte. Ambas direcciones son válidas y alcanzan actualidad en la novela de Arguedas. Porque es un hecho innegable que la representación apocalíptica de Chimbote apela tanto a la coyuntura real e histórica del Perú como a la propia biografía del autor.

En el primer caso, una larga cita de Julio Ortega ilustra la transformación de Chimbote que, en pocos años, deja de ser una tranquila caleta de pescadores para convertirse en el mayor puerto pesquero del mundo:

La industria de la harina de pescado convirtió a la caleta en el puerto pesquero más grande del mundo y al Perú en el primer productor mundial de ese valioso insumo. En los años 60, cien mil personas,

"Arguedas vivía un infierno interior: su novela pintará un mundo infernal" (Vargas Llosa, La utopía 299).

${ }^{9}$ Un paso importante en la trayectoria del pensamiento apocalíptico es la idea de San Agustín según la cual el apocalipsis debía ser entendido como "una alegoría espiritual en vez de una descripción política" real y concreta (Parkinson 31). Frank Kermode ha identificado este giro hacia la alegorización con el surgimiento del "concepto moderno de crisis" (33), entendido como el resultado del desplazamiento desde la significación del tiempo histórico individual en función del fin colectivo de la humanidad, hacia la significación del tiempo histórico individual en función de la propia muerte. 
mayormente migrantes andinos, se hacinaban en las precarias "barriadas" levantadas en sucesivas invasiones de terrenos arenosos e insalubres. Dos décadas más tarde, la ciudad de doscientos mil habitantes estaba coronada por el humo de las plantas y cercada por el mal olor del procesamiento del pescado. Las playas fueron destruidas por la industria pesquera, que había crecido sin planeamiento dentro del área urbana y arrojaba sus desperdicios directamente a la bahía, hoy día un desastre ecológico, de aguas muertas, cercadas por un cordón sanitario de rocas, infectado de ratas. La repentina prosperidad llenó al puerto de construcciones y negocios pero también de bares, burdeles y violencia. Los sindicatos, los partidos políticos, las alzas y bajas de la pesca indiscriminada, los precios del mercado internacional, la monoproducción, los mercados ambulantes, convirtieron al paisaje urbano y humano en una poderosa y contradictoria versión de la modernización compulsiva. Huelgas, invasiones de terrenos, conflictos legales, enfrentamientos con la policía, subrayaban el proceso caótico y dinámico, pero también desigual y agónico, de este populoso emblema del desarrollo peruano ("Los Zorros" s/n).

La modernización de Chimbote -y del Perú- a raíz del auge de la industria pesquera respondió más a una oportunidad repentina que a un programa de desarrollo ${ }^{10}$. Las millonarias utilidades se concentraron en muy pocas manos privadas, algunas de ellas extranjeras, lo que significó perder la oportunidad de hacer significativa y extensiva la riqueza en términos de la nación. "País de oportunidades perdidas" apodó Jorge Basadre al Perú (en Bryce, A trancas 78). Las consecuencias sociales derivadas de la rapidez con la que se produjo el crecimiento del trabajo y de la urbe crearon un escenario nefasto para el progreso humano: corrupción y mafia, abuso laboral y discriminación contra la mujer, desigualdad extrema en la distribución de los ingresos, migración descontrolada desde la zona andina, desastre ecológico, son algunos de los potros sobre los que se cabalgó hacia el vaciamiento de sentido y la

${ }^{10}$ Algunos datos con las que argumentar esta idea son: a) agotamiento del recurso: entre 1968 y 1970 se capturaban más de 12 millones de toneladas de anchoveta al año, cifra que bajó a poco más de 3 millones en 1975 y a 725,000 toneladas en 1980; b) mafia en torno a la industria: el primero de enero de 1972, Luis Banchero Rossi ("Braschi” en la novela), el empresario pesquero más importante, es asesinado; c) ausencia de proyecto pesquero: mientras que el auge de la pesca llega a su punto más alto entre 1968 y 1970, recién en el año 1971 se constituye el Ministerio de Pesquería, y en 1973 se estatiza la industria. Véase Franklin Pease (Breve historia). Véase también Pablo Macera y Santiago Forns (Nueva crónica). 
deshumanización. La realidad, entonces, ofrecía a Arguedas un contexto apocalíptico sin mayor necesidad de hiperbolizarla para su ficcionalización. Obsérvese, por ejemplo, la descripción que hace del hedor que caracterizaba el puerto de Chimbote (en este caso el novelesco pero también vale para el real):

La fetidez del mar desplazaba el olor denso del humo de las calderas en que millones de anchovetas se desarticulaban, se fundían, exhalaban ese olor como alimenticio, mientras hervían y sudaban aceite. El olor de los desperdicios, de la sangre, de las pequeñas entrañas pisoteadas en las bolicheras y lanzadas sobre el mar a manguerazos, y el olor del agua que borbotaba de las fábricas a la playa hacía brotar de la arena gusanos gelatinosos; esa fetidez avanzaba a ras del suelo y elevándose (50).

Sin embargo, no es la destrucción ecológica la que se lleva la mayor responsabilidad de generar un apocalipsis en El zorro de arriba y el zorro de abajo, sino, más bien, el complejo proceso de modernización. Los distintos espacios simbólicos que constituyen la novela y las dinámicas sociales que en ellos se inscriben así lo evidencian: el burdel, el mercado, el cementerio, la barriada, la fábrica, aglutinan las contradicciones y falencias de la modernidad peruana y constituyen los núcleos de un imaginario apocalíptico actualizado en su faceta distópica y destructiva. Pero más que cada uno de estos espacios en particular, interesa aquí detenerse en un personaje que deambula entre esos espacios, vinculándolos pero al mismo tiempo haciendo evidente los intersticios entre ellos, y que, sumido en una 'locura profética', constituye la voz con la que estalla la irracionalidad del proceso modernizador en el Perú. Se trata del 'loco' Moncada, como es conocido en Chimbote. En su quehacer profético, aborda algunos de los grandes problemas que han obstaculizado la modernización de la nación o cuestiona los modos que ha ido adquiriendo la modernidad. Su 'locura' le da, paradójicamente, la lucidez necesaria para denunciar problemas reales del Perú republicano, tales como la explotación de recursos naturales a manos de corporaciones extranjeras, que es lo que muestra el siguiente ejemplo: "Aquí, en el Perú que decimos, después de San Martín, don José, no ha habido sino forasteros, extranjeros que han mandado. Nosotros no semos [sic] sino sirvientes extranjeros..." (69). Cual propheta medieval, Moncada carga una cruz que estaciona en distintos lugares de Chimbote, siempre públicos y populosos, desde los cuales articula sus 
discursos. Y cual actor carnavalesco, encarna distintos personajes según la intención del acto performativo de su performance:

"Yo soy torero del Dios, soy mendigo de su cariño, no del cariño falso de las autoridades, de la humanidad también ¡Miren!” ... "Miren cómo toreo las perversidades, las pestilencias. Yo soy lunar negro que adorna la cara; el lunar cuando está en la mejilla de la mujer buenamoza o en la frente del hombre, es adorno. ¿Quién dice que no? Yo soy lunar de Dios en la tierra, ante la humanidad. ... Toreo; no me cornea ninguna de las tentaciones que hacen rico a Braschi, al comerciante Mohana que quiso ser alcalde. Ahora ya los toros no me embisten; todos han sido toreados. ... Yo soy esa pestilencia, aquí estoy sudando la bubónica de Talara-Tumbes, Internacional Petrolium Company, Esso, Lobitos, libra esterlina, dólar" (65-66). "Orbegozo Moncada, presidente del Perú, dueño de la hacienda Moncada. ¡Never!” (67).

El lenguaje religioso vinculado a lo apocalíptico tiene otras versiones en el texto, aparte de la del loco Moncada. Reiteradas referencias al profeta Isaías y a las epístolas de Pablo, iglesias de culto evangélico que instruyen a los pobladores en el texto bíblico, curas cristianos defensores de la teología de la liberación que cuelgan el retrato del Che Guevara junto al de Cristo y exhortan a la búsqueda de justicia por medio de la revolución, son algunos de los componentes que dan espesor profético al discurso novelesco. Pero hay un acontecimiento que expresa patéticamente el costo del progreso. En el segundo capítulo de la novela, los pobladores de la barriada reciben la orden de enterrar a sus 'nuevos' muertos en una pampa-hondonada que quedaba cerca del basural del puerto, porque el cementerio que estaban utilizando ya no tenía más espacio para ellos. La explosión demográfica de los muertos acompaña la de los vivos. Aunque no se les obliga a cambiar los cadáveres, hombres y mujeres deciden trasladar a pie de un cementerio a otro las cruces de sus deudos. La procesión fúnebre que entonces tiene lugar, en la que cientos o miles de pobladores cargan una, dos o hasta cinco cruces a través de todo Chimbote, pone en primer plano el sentido a la vez sufriente y comunitario de quienes podrían considerarse las 'víctimas expiatorias' del proceso de modernización.

Con las cruces al hombro se acercaron todos a la fila de maderos que tenían las leyendas de sus nombres hacia el arco, las alzaron por la cabeza y se las pusieron al otro hombro. Y cada deudo desfilaba, 
médano abajo, con cruces sobre los dos hombros. Formaban así una comitiva muy grande que bajaba levantando polvo, una masa de gente avanzaba sin hablar (77).

Encontrar un sentido a este sufrimiento y ver en él una posibilidad de renovación es el significado atribuido a esta vía crucis. Una prostituta, por ejemplo, 'reza' en quechua: "Asco, asco ¡ay! Como no habrá jamás de los jamases. Gracias, cruces santas, errantes, como yo, botadas. A tus luces he mirado el asco de mi vida, como he pisoteado mi vida" (82). No será la única vez que la literatura apocalíptica peruana muestre una procesión de este tipo, que enraíza tanto con el cristianismo primitivo como con sus manifestaciones populares durante la Edad Media ${ }^{11}$. Julio Ortega ha escrito que este desfile convierte "a la ciudad en una necrópolis" y, sobre el lenguaje bíblico transversal a toda la novela, cree que "posibilita una mediación entre la vida sin sentido y la muerte sin discurso. ... esta dimensión mítico-religiosa, esta persuasión cristiano-primitiva, posibilita articular la diáspora andina en la modernización desnaturalizadora como un sacrificio patente y un renacer latente" ("Los Zorros" s/n).

Se ha dicho más arriba que la representación apocalíptica de Chimbote apela no solo a la historia del Perú sino a la biografía del propio autor (la crisis del contexto y la crisis del sujeto). Para iluminar este segundo caso, es necesario escarbar en los personajes que pueblan el Chimbote de la novela y el Chimbote real de fines de la década del sesenta. En ambos casos, se trata de gente que 'descendió' desde la sierra para trabajar en el puerto pesquero. Todos comparten un mismo rasgo, el de ser sujetos migrantes; pobladores principalmente de la zona andina, quechua hablantes, huyendo de las precarias y letales condiciones de trabajo de las minas de los Andes o de la explotación cuasi-feudal de las grandes haciendas: "Parobamba, pueblito andino, nu'hay esperanza: chanchito, ovejita, chacrita chico, uno, dosito. Hacienda grande también silencio, obediencia, boca cerrado. Silencio comen allá, alturas, sierra que decimos, compadre" [sic] (176). Todos llegan a la costa seducidos por la -efímera e incierta- bonanza económica del puerto o, simplemente, por un entorno propicio para la supervivencia. Según la descripción de Cornejo Polar, "indios y mestizos andinos, que prefirieron

11 También la novela de José B. Adolph, Mañana, las ratas, contiene una procesión de flagelantes y, curiosamente, aborda igualmente el tópico de la modernidad en el Perú. 
enfrentarse a la temible amenaza del mar, recién descubierto, y a maquinarias nunca vistas, ciertamente también aterrorizantes, que repetir su inacabable y secular servidumbre" ("Condición migrante" 102). El paso de una cultura andina con fuertes contenidos míticos a una costeña plagada de cristales (brillantes pero también frágiles e hirientes) de modernidad, los distintos grados de aculturación y bilingüismo, el desarraigo y el sentimiento de una identidad fracturada, la dificultad de establecer vínculos de pertenencia en una comunidad por definición heterogénea, son algunos de los retos que el sujeto migrante debe enfrentar desde el momento en el que proyecta un horizonte de vida con un sentido mayor (o al menos diferente) al que tendría antes de la migración.

La condición del migrante recién mencionada describe parcialmente una situación de crisis que -mutatis mutandis, dada su formación intelectualArguedas exhibe y proyecta en su escritura. Nacido en la sierra en una familia de 'blancos' e 'hispanohablantes', sus lazos afectivos infantiles los establece con los sirvientes indios de la casa, haciendo del quechua prácticamente su idioma materno. La reivindicación de esta doble referencia cultural y afectiva estará presente hasta el final de su vida. En los diarios escribe: "He sido feliz en mis llantos y lanzazos, porque fueron por el Perú; he sido feliz con mis insuficiencias porque sentía el Perú en quechua y en castellano" (287). También cuando recibe el premio "Inca Garcilaso de la Vega", pronuncia un discurso en el que reincide sobre su doble filiación: "Yo no soy un aculturado; yo soy un peruano que orgullosamente, como un demonio feliz habla en cristiano y en indio, en español y en quechua" ( $E l$ zorro 297). Cómo saber si el "demonio feliz" hecho del español y del indio que convivieron orgullosamente en Arguedas (condición siempre doble, nunca una síntesis mestiza) se convirtió en algún momento en un demonio fatídico que desarmonizó su vida al punto de enemistarlo irrevocablemente con ella. Nunca lo sabremos. Pero eso no impide ver la situación común - de crisis apocalíptica, de identidad desgarrada enfrentada a la vida y a la muerte- entre los migrantes de su novela y su propia vida.

La expresión más fuerte de la situación del sujeto migrante viene dada en la novela por su lenguaje. En el lenguaje no habita únicamente el mundo que se consigna, sino también los medios para cifrarlo. El lenguaje sitúa en un mismo nivel de importancia los modos para narrar la historia y la historia misma. Al individuo en su lenguaje no le es suficiente el entendimiento de los acontecimientos sino que se empeña en encontrar la fórmula para revelarlos. Esta descripción del uso del lenguaje en la novela coincide precisamente 
con otro de los motivos apocalípticos señalados por Parkinson: el doble esfuerzo en un sujeto único, el narrador apocaliptista, que concentra la responsabilidad de receptar-lo visto, lo oído, lo vivido- y de re-emitirlo para sus contemporáneos. Acto comprensivo y comunicativo al mismo tiempo; desciframiento y reciframiento. Al igual que los dos motivos anteriores, éste se articula también en la novela de Arguedas a partir del singular lugar de enunciación del texto y, desde allí, se proyecta al tercer estrato textual, los mitos pre-hispánicos, en el que se despliega la cara epifánica del apocalipsis. "Estos «Zorros» se han puesto fuera de mi alcance", escribe Arguedas en su "Tercer diario", "corren mucho o están muy lejos. Quizá apunté un blanco demasiado largo o, de repente, alcanzo a los «Zorros» y ya no los suelto más" (211).

La forma lingüística en El zorro de arriba y el zorro de abajo ha sido estudiada por Antonio Cornejo Polar, quien la ha descrito a partir de la condición migrante de los personajes emisores de los discursos y de la condición migrante del propio narrador. A diferencia del sujeto mestizo que produce un sincretismo entre sus dos vertientes culturales y en términos de su lenguaje realiza una "fusión en el nivel de la lengua «culta»", el sujeto migrante aglutina en el sintagma la más amplia constelación semántica posible "para acoger las voces múltiples de sus ancestros dialogantes". El sujeto migrante no suprime, desde el criterio de la cultura dominante, su doble (o múltiple) procedencia. Por el contrario, yuxtapone lenguas, sociolectos, sin más síntesis que la necesaria para garantizar el acto comunicativo. Se trata de una "producción de discursos encabalgados en varias culturas, conciencias e historias", explica Cornejo Polar ("Condición migrante" 105). Este aspecto que atañe al lenguaje y a la identidad de los sujetos simultáneamente está alegorizado en la novela por la presencia de dos animales dialogantes, el zorro de arriba y el zorro de abajo, animales míticos que provienen de una serie de relatos recopilados en una región andina bajo el título Dioses y hombres de Huarochirí a fines del siglo XVI por el cura Francisco de Ávila. Las leyendas fueron luego traducidas del quechua por José María Arguedas. A pesar de ser la capa textual que menos páginas ocupa en la ficción, los zorros le dan el título a la novela, detalle suficientemente elocuente de la importancia simbólica de estos personajes y de su función.

La procedencia de arriba y de abajo hace referencia a la sierra y a la costa. En sus cortos diálogos, los zorros intercambian información de ambos mundos, dando algunas pistas de las transformaciones que ocurren con las personas cuando se desplazan de una zona a otra, así como de sus temores y esperanzas: 
El zORRO DE ARRIBA: La Fidela preñada; sangre; se fue. El muchacho estaba confundido. También era forastero. Bajó a tu terreno.

El zorRo DE ABAJO: Un sexo desconocido confunde a ésos. Las prostitutas carajean, putean, con derecho. A nadie pertenece la "zorra" de la prostituta; es del mundo de aquí, de mi terreno. Flor de fango, les dicen. En su "zorra" aparece el miedo y la confianza también (31-32).

El "talante andariego de los animales legendarios", como dice Cornejo Polar ("Condición migrante" 102), es una de las claves para vincular a los zorros con la condición migrante de personajes y narrador y con toda la complejidad lingüística propia de dicha condición. Los zorros hablan en algunas ocasiones en quechua (la traducción viene a continuación entre corchetes) y en otras en castellano, utilizan esa misma concatenación de palabras que caracteriza el lenguaje del migrante, expresan la inutilidad del lenguaje verbal para hacer inteligible algunos de los aspectos del mundo y muestran la doble preocupación arriba mencionada por la historia y por los modos de narrarla:

El zORRO DE ABAJO: ¿Entiendes bien lo que digo y cuento?

El zorro de ARriBa: Confundes un poco las cosas.

El zorRo DE ABAJO: Así es. La palabra, pues, tiene que desmenuzar el mundo. El canto de los patos negros que nadan en los lagos de altura, helados, donde se empoza la nieve derretida, ese canto repercute en los abismos de roca, se hunde en ellos; se arrastra en las punas, hace bailar a las flores de las yerbas duras que se esconden bajo el ichu, ¿no es cierto?

El zORRO DE ARRIBA: Sí, el canto de esos patos es grueso, como de ave grande; el silencio y la sombra de las montañas lo convierte en música que se hunde en cuanto hay.

EL ZORRO DE ABAJO: La palabra es más precisa y por eso puede confundir. El canto del pato de altura nos hace entender todo el ánimo del mundo. Sigamos. Éste es nuestro segundo encuentro. Hace dos mil quinientos años nos encontramos en el cerro Latausaco, de Huarochirí (60).

Una de las cosas que queda al descubierto en los diálogos entre los zorros es justamente su condición dialógica. El consenso buscado entre las partes -entre los zorros- mientras construyen el mundo que narran, al tiempo que lo vinculan al pasado y al futuro, conlleva el gesto del sujeto migrante en su 
lenguaje y el del propio Arguedas: el de la yuxtaposición sin síntesis. Se trata de reunir sin suprimir, de sumar sin jerarquizar. Y es en este mismo gesto que se funda la visión utópica de la novela. Porque el mundo representado ha dado cuenta fundamentalmente de la versión más destructiva y catastrófica del apocalipsis. No son frecuentes los testimonios de los personajes en los cuales se deje traslucir un toque de esperanza. Y cuando lo hacen, muchas veces esta mirada está dirigida hacia el pasado remoto, casi mítico, de la cultura prehispánica: “A mi lado el Inca está, cuando llegamos a la mar alto. Atalhualpa nu'está muerto ... El Inca a mi lado, más cuando en mi frente siento el bulla profondo del anchoveta. ¡Ahistá el Inca, a mi lado, tranquilo, como bulto, altazo, sen color! [sic]" (223). Sin embargo, en la forma de narrar se ha revelado la esperanza de un nuevo mundo que mira hacia el futuro, emergiendo la versión más consoladora del imaginario apocalíptico. La epifanía del lenguaje que viene del diálogo canta al dialogismo cultural, a la heterogeneidad del mundo peruano, a la reunión de todas sus sangres. Esta es la alegoría de estos zorros que, aún siendo de arriba y de abajo, encuentran en el diálogo respetuoso el espacio para la comunicación. En los zorros, Arguedas manifiesta su revelación verdaderamente apocalíptica, aquella con la que en el “¿Último diario?” se despide de la novela y de la vida:

Y ese país en que están todas las clases de hombres y naturalezas yo le dejo mientras hierve con las fuerzas de tantas sustancias diferentes que se revuelven para transformarse al cabo de una lucha sangrienta de siglos que ha empezado a romper, de veras, los hierros y tinieblas con que los tenían separados, sofrenándose. Despidan en mí a un tiempo del Perú cuyas raíces estarán siempre chupando jugo de la tierra para alimentar a los que viven en nuestra patria, en la que cualquier hombre no engrilletado y embrutecido por el egoísmo puede vivir, feliz, todas las patrias (287).

\section{BIBLIOGRAFÍA}

Arguedas, José María. El zorro de arriba y el zorro de abajo. Buenos Aires: Losada, 1971.

"No soy un aculturado". El zorro de arriba y el zorro de abajo. Buenos Aires: Losada, 1971.

Befumo Boschi, Liliana y Aymara de Llano. "El escritor y el hombre desde el narrador en

'Los Zorros ...' de José María Arguedas". Revista de Crítica Literaria Latinoamericana,

Vol. 11. No 21/22 (1985): 173-192.

Bryce Echenique, Alfredo. A trancas y barrancas. Lima: Peisa, 1999. 
Cornejo Polar, Antonio. Los universos narrativos de José María Arguedas. Buenos Aires: Losada, 1973.

"Condición migrante e intertextualidad multicultural: el caso de Arguedas". Revista de Crítica Literaria Latinoamericana, Vol 21. № 42 (1995): 101-109. 2000.

Literatura peruana. Lima: Centro de Estudios Literarios “Antonio Cornejo Polar”,

Díaz Caballero, Jesús. "La transculturación en la novela regionalista: el caso sur andino peruano y la obra de Arguedas". Revista de Crítica Literaria Latinoamericana, Vol. 13. $\mathrm{N}^{\mathrm{o}} 25$ (1987): 155-172.

Esparza, Cecilia. El Perú en la memoria. Sujeto y nación en la escritura autobiográfica. Lima: Red para el Desarrollo de las Ciencias Sociales en el Perú, 2006.

Focant, Camile. “El Apocalipsis de Juan. Género literario, estructura, recepción”. Geneviève Fabry, Ilse Logie y Pablo Decock (eds.). Los imaginarios apocalípticos en la literatura hispanoamericana contemporánea. Bern: Peter Lang, 2010. 35-52.

García-Bedoya, Carlos. Para una periodización de la literatura peruana. Lima: Universidad Nacional Mayor de San Marcos, 2004.

Kermode, Frank. El sentido de un final. Estudios sobre la teoría de la ficción. Barcelona: Gedisa, 1983.

Lienhard, Martín. “Tradición oral y novela: Los 'Zorros' en la última novela de José María Arguedas”. Revista de Crítica Literaria Latinoamericana, Vol. 3. Nº 6 (1977): 81-92.

Macera, Pablo y Santiago Forns. Nueva crónica del Perú siglo XX. Lima: Fondo Editorial del Congreso del Perú, 2000.

McGinn, Bernard. "Introduction: John's Apocalypse and the Apocalyptic Mentality". The Apocalypse in the Middle Ages. McGinn, Bernard y Richard Emmerson eds. Ithaca: Cornell University, 1993

Meynet, Roland. Leer la biblia. México: Siglo XXI, 2003.

Morales Ortiz, Gracia María. “'Heterogeneidad' y 'Totalidad’: Dos conceptos teóricos de Cornejo Polar aplicados a los textos de Arguedas". Revista de Crítica Literaria Latinoamericana, Vol. 25. No 50 (1999): 187-197.

Ortega, Julio. "Los Zorros de Arguedas: migraciones y fundaciones de la modernidad andina". Prólogo a la traducción de El zorro de arriba y el zorro de abajo (University of Pittsburgh Press, traducción de Frances Barraclough, edición de Julio Ortega). Disponible en: www. andes.missouri.edu/andes/Especiales/JOZorros/JO_Zorros1.html.

Parkinson, Lois. Narrar el Apocalipsis. México: Fondo de Cultura Económica, 1996.

Pease, Franklin. Breve historia contemporánea del Perú. México: Fondo de Cultura Económica, 1998.

Rowe, William. "Música, conocimiento y transformación social". Revista de Crítica Literaria Latinoamericana, Vol. 13. № 25 (1987): 97-107.

Sagrada Biblia. Versión directa de las lenguas originales por Eloíno Nácar y Alberto Colunga. Madrid: La Editorial Católica, 1960. 
Schaeffer, Jean-Marie. "Del texto al género. Notas sobre la problemática genérica”. Miguel A. Garrido Gallardo (comp.). Teoría de los géneros literarios. Madrid: Arco/Libros, 1988. 155-179.

Seco, Manuel. Diccionario del español actual. Madrid: Aguilar, 1999.

Vargas Llosa, Mario. La utopía arcaica. José María Arguedas y las ficciones del indigenismo. México: Fondo de Cultura Económica, 1997.

Vokral, Edita. “Arguedas como dansak' en la lucha por la cultura andina”. Revista de Crítica Literaria Latinoamericana, Vol. 10. № 20 (1984): 297-303. 